\title{
Reform and Practice of Teaching Model of "Security Design and Validation" Based on Flipped Classroom
}

\author{
Kan Lijuan, Xu Jihui, Li Ze \\ School of Equipment Management and UAV Engineering \\ Air Force Engineering University \\ Xi'an, Shaanxi, 710051
}

\begin{abstract}
Flipped classroom as a new teaching concept effectively fills in the gaps of the traditional teaching mode by shifting instruction to a learner-centered model, delivering instruction online and offline with the aid of network and technology. A teaching model reform was conducted on the course Security Design and Validation based on the flipped classroom, forming a teaching philosophy of "one goal, two roles, three reforms, and four foundations". A modular "course package" teaching content system was built based on "analysis + design+ verification+ practice". A "five ring" teaching design model was proposed with "question, design, knowledge, method, application". The mixed teaching mode was practiced based on Flipped classroom's "self-study offline, problem explanation, display in class, group discussion, after-class extension”. By recording micro-knowledge and micro-video, students will be guided to self-study before class, and discuss problems in the class, and after-school extended assistance will be arranged. All these measures have effectively integrated "teaching" and "learning", strengthened the subjective status of students and improved the teaching effect.
\end{abstract}

Keywords-flipped classroom; micro course; "five rings"; instructional design; teaching mode

\section{INTRODUCTION}

In recent years, the flipped classroom has become more and more popular in the education community with the activities such as "National Flipped Class Meeting" and "Flipped Classroom Teaching Observation Seminar" held, and it is likely to defeat other teaching models. Flipped Classroom, also known as "reverse classroom", is a type of blended learning that uses video teaching as a carrier. In a flipped classroom, students watch online lectures before class and engage in concepts in the classroom with the guidance of a mentor in class. In essence, it is a mixed learning model that combines traditional face-to-face classroom instruction with online teaching ${ }^{[1]}$. In 2007, Jonathan Bergmann and Aaron Sams, chemistry teachers at Woodland Park High School in Colorado, USA, recorded their lectures and posted them online in order to accommodate students who missed their classes, and thus developed the "Flipped-Mastery" model. In 2011, Salman Khan, a hedge fund analyst at Connective Capital Management, who founded Khan Academy, a free online education platform, which was reported by the American "Economist" magazine, sparking an open educational resource movement ${ }^{[2]}$. At present, the flipped classroom has swept the world and attracted the attention of circles of education.

He Kekang (2014) expounded the origin and development of the flipped classroom and explored its essential characteristics ${ }^{[3]}$. Dong Liming et al. (2014) explored the application mode of the flipped classroom concept in the course teaching, and analyzed the characteristics of the model application and the influencing factors of the development ${ }^{[4]}$. Zhou Ping (2015) analyzed the flipped roles of teachers and students in the classroom, the flipping of the learning process, the flipping of the teaching environment, etc., and proposed the teaching design theory, constructivist theory and learn-through-play theory ${ }^{[5]}$. In flipped classroom, students will learn by themselves the knowledge previously delivered by teachers through watching the teaching resources, courseware, exercising, etc. and raise questions, figure out the difficulties by teacher's instruction, peer's collaborative exploration and interactions so as to achieve knowledge internalization.

\section{Security Design and Validation Flipped Class Mode DESIGN}

Security Design and Validation is a basic compulsory course for junior students in safety engineering with strong theoretical and practical and a high requirement on student's self-study. Focusing on the problems of students' weak awareness of self-study, insufficient offline resources, short of cooperation opportunity and poor tuition from teachers in traditional teaching model, this article demonstrates the reform of Security Design and Validation flipped class to stimulate students' interest, improve their ability to self study so that to promote the course quality.

\section{A. Teaching Philosophy}

Bases on flipped class as instruction, this theory advocates "Teaching House" model which forms a teaching reform philosophy of "facing one goal, exploit two advantages, deepen three reforms and consolidate four foundations". The first on is facing one goal, representing the improvement of students' scientific quality and engineering practical ability to carry out security analysis, design and validation. The second is exploiting two advantages, representing the advantages of training and guidance. The third is deepening three reforms, i.e. reform on teaching methods and assessment model. The forth 
is consolidating four foundations of innovation in teaching theories, improvement on ability of teaching group, construction of teaching resources in high quality and development of teaching online platform.

\section{B. Teaching Model}

This article constructs a teaching model of flipped class in line with teaching characteristics in colleges and the model is set out as below ${ }^{\text {IT? }}$ :

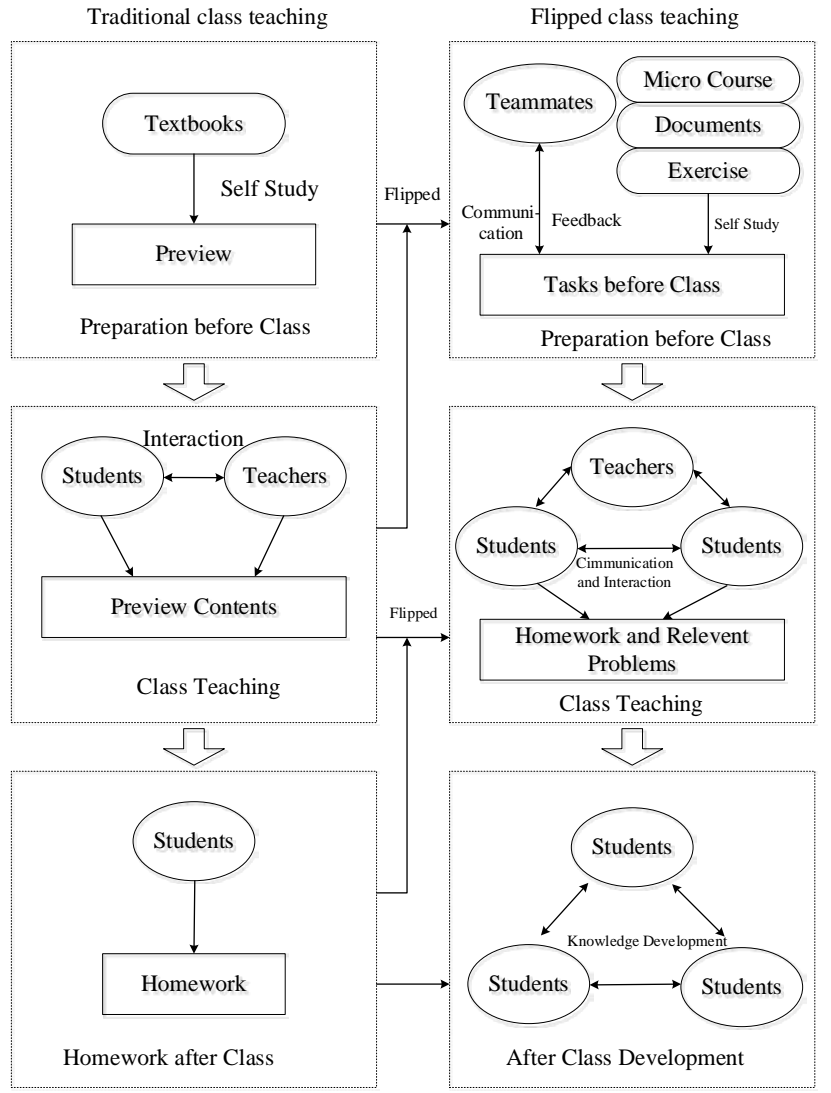

Fig. 1. Security Design and Validation flipped teaching mode

\section{The Content System of "Course Pack"}

This pack establish a pack course system of "analysis theories plus design theories plus validate theories and plus thematic practice" including two parts of theory and practice. The system is set out as below.

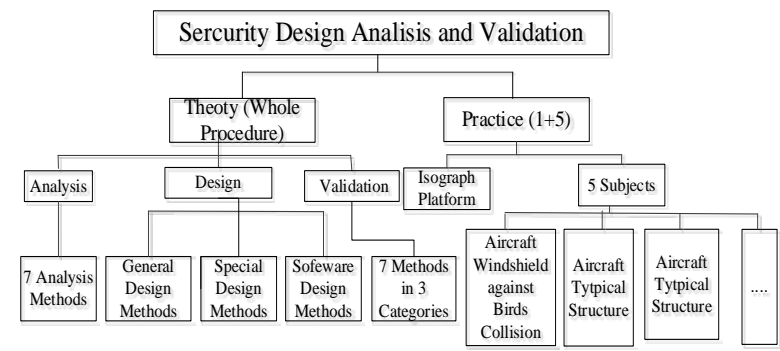

Fig. 2. Teaching content systembased on "course package"

\section{D. "Five Rings" Teaching Design Model}

On the basis of the status quo of knowledge system, structural framework and supporting resources, this paper proposes the five-ring teaching design model of "question ring, design ring, knowledge ring, method ring and application ring" to guide the teaching concept and teaching process, activities, the development of knowledge points, teaching methods, and interactions between students and teachers. It is shown in Fig. $3^{[6]}$.

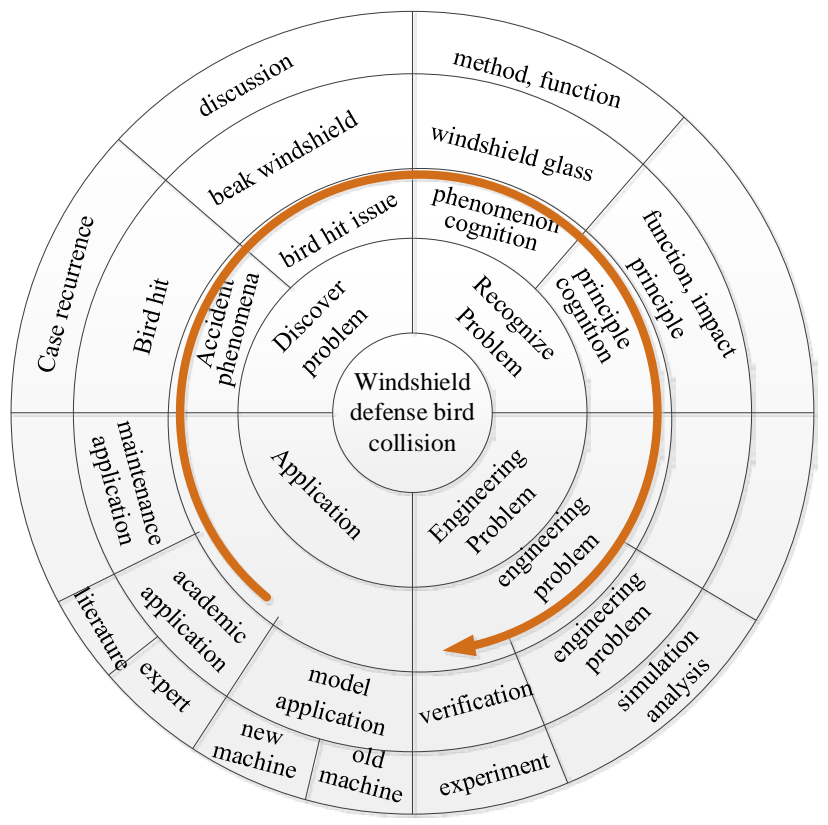

Fig. 3. "Five rings" teaching design model

\section{Security Design and Validation Teaching Practice OF FLIPPED CLASS}

\section{A. Design and Production of Micro lecture}

First, select the material that is suitable for the flipped class as a micro unit according to the course teaching objectives and content. Second, design the self-learning task for each micro unit. Simply put, it's the pre-class task that students have to complete before teaching, including learning tasks and resources, practice content and question files etc. Students can make their own studying plans based on their learning tasks, and complete the pre-class tasks. Third, prepare each micro unit. On the basics of having a good understanding of the knowledge and teaching focus, prepare the teaching content, write the shooting scripts and collect the multimedia materials. Last, compile the micro-tests in line with the teaching objectives and focus of each micro unit. The testing quantity shouldn't be too many, and the difficulty level should be moderate. Designed with appropriate quantity and difficulty level, the testing must present challenge in order to stimulate students' learning interest.

\section{B. Organization and Implementation of Flipped Class}

The first step is offline self-learning. Take the concept of security design and 14 kinds of general security design methods as the 15 knowledge points. Then record them as the micorlecture and upload to the college teaching and research network platform for students' self-learning. Students can watch the micro videos repeatedly and finish the online testing. Also, they can make an online discussion on difficult question 
in the course forum. Then, the teachers are able to know what the students' learning difficulties are according to the video clicks. Also, they can know students' learning status based on the answers. And they can participate in the online discussion and give answers for students.

The second step is question explanation. In the classroom, the teachers answer the generative questions from students' offline learning. The generative questions are generated according to the micro videos clicks, online testing results and the related questions of the course discussion panel.

The third step is class presentation. Combine with their knowledge; students explain the security design method of a certain product to everyone, which aims at analyzing the application of theoretical knowledge in practice.

The forth step is group discussion. Focus on the topic of security design, each team will present the results of the typical case studies that they are responsible for, and discuss and exchange views with the others. The design theory will be applied in practice. And each group will receive others' evaluations after the presentation.

The fifth step is expansion after class. Students can continue to read the literature related to security design and take the knowledge of general security design methods into practice, so as to consolidate their knowledge.

\section{Effectiveness Evaluation of Flipped Class}

To obtain the objective understanding of the practice effect of flipped class and the feedback information from the students, the questionnaire method is used to analyze the teaching resources of flipped classroom, learning effect and acceptance level of teaching model that compared with the traditional class. The questionnaire is targeted at the junior students majoring in security engineering in the teaching reform class. A total of 16 valid questionnaires have been distributed and recovered. The results analysis are as follows:

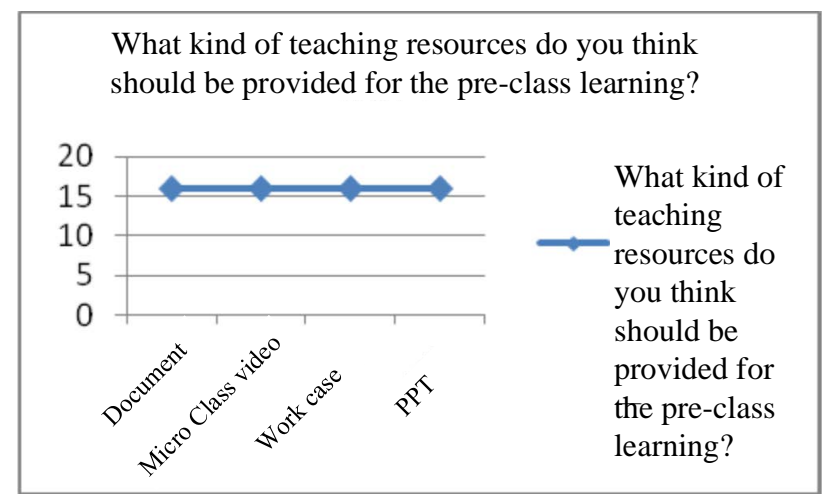

Fig. 4. Survey result of "the kind of teaching resources"

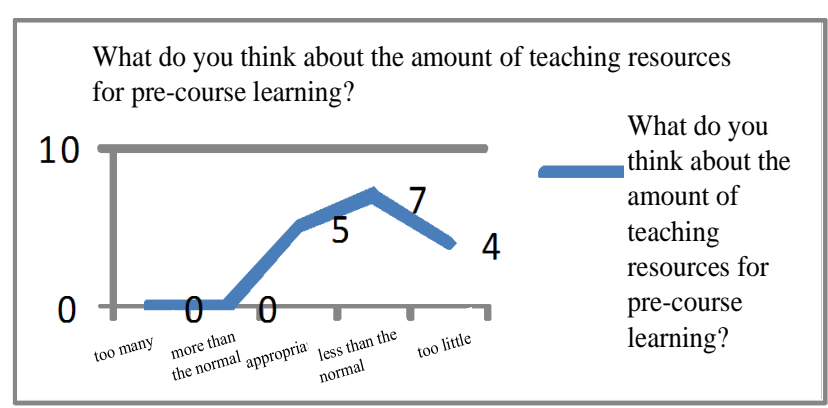

Fig. 5. Survey result of "the amount of teaching resources”

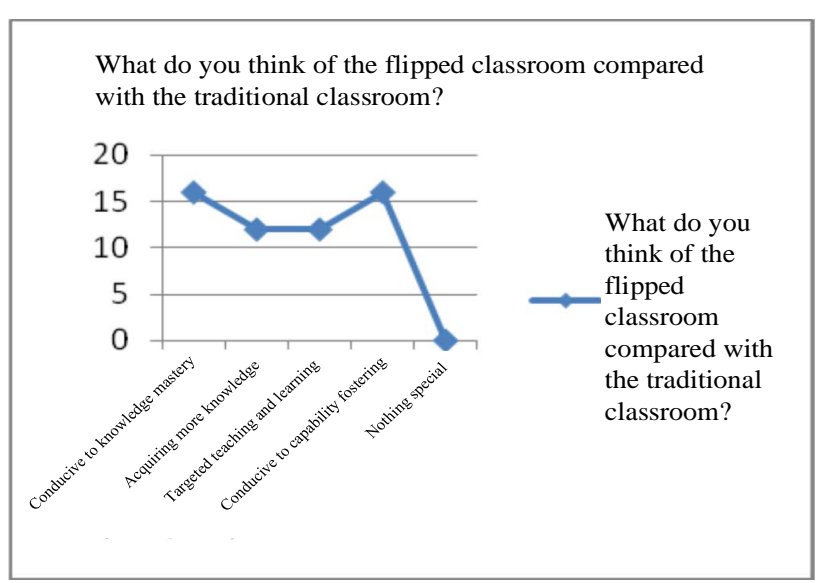

Fig. 6. Survey result of "the comparison between two different teaching models"

Are you willing to continue the pilot of the flipped classroom teaching?

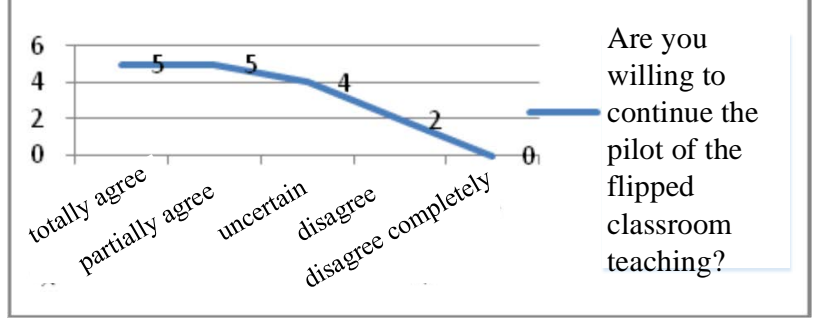

Fig. 7. Survey result of "the attitude to the flipped classroom teaching”

The results indicate that flipped class teaching of this course is successful. The students generally prefer this new learning mode. They believe this approach really achieve "My study lies in my own decision” and realize that Security Design and Validation is a very important and challenging learning task. Since then, the students have more learning problems to think about, and the attitude and initiative have significantly improved, which are conducive to the cultivation of students' abilities.

\section{CONCLUSION}

Through the Security Design and Validation teaching practice of flipped class, this paper designs the teaching mode of flipped class based on "offline self-learning, question explanation, class presentation, group discussion and expansion after class, realizing one class flips between class 
teaching and pre-class preparation, and one between homework and class teaching. The practice has proved that flipped class realizes the deep integration of information technology and teaching contents and methods, which makes up for the lack of "teaching first learning second" mode in traditional type. And this new teaching mode better stimulate the initiative and exploration of students' learning, which is conducive to the improvement of students' comprehensive ability and quality and effectively supporting and promoting the cultivation of innovative talents.

\section{REFERENCES}

[1] Chen Yukun, Tian Aili. Introduction to MOOC and Flipped Classroom [M].East China Normal University Press, 2014.

[2] Zhang Futao. Flipped Classroom Theory and Practice [M].Shandong Friendship Publishing House, 2014.

[3] He Kekang. On the Development of Flipped Classroom from Its Nature [J].E-education Research, 2014(07).

[4] Dong Liming, Jiao Baocong. On the Teaching Application Model Based on Flipped Classroom Idea [J].E-education Research, 2014(07).

[5] Zhou Ping. On Flipped Classroom Based on Modern Educational Technology and Its Theory [J].Computer-Assisted Foreign Language Education, 2015(02)

[6] Xu Jihui. On the Reform of Teaching Model of Security Design and Validation Based on Flipped Classroom [D]. A ir Force Engineering University, 2016.

[7] Jin Yan. Practical Research on the Teaching Mode of Flipped Class Based on micro class- Taking Basics of Computer Applications as an Example[J].Vocational \& Technical Education Forum,2014(23):55-58 